\title{
Modelling the simultaneous calcination/sulfation behavior of limestone under circulating fluidized bed combustion conditions
}

\author{
Liang Chen ${ }^{1}$, Chunbo Wang ${ }^{1}$, Tong $\mathrm{Si}^{1}$, Edward J. Anthony ${ }^{2 *}$ \\ ${ }^{1}$ School of Energy and Power Engineering, North China Electric Power University, Baoding 071000, \\ China \\ ${ }^{2}$ School of Power Engineering, Cranfield University, Cranfield, Bedfordshire MK43 0AL, UK \\ ${ }^{*}$ Corresponding author. E-mail address: b.j.anthony@cranfield.ac.uk
}

\begin{abstract}
The simultaneous calcination/sulfation (SCS) reaction is the realistic reaction process for limestone use in CFB boilers. A SCS reaction model based on the randomly-overlapped pore concept, which takes into consideration the calcination of $\mathrm{CaCO}_{3}$, the sulfation of $\mathrm{CaO}$ and the sintering effect simultaneously, was developed. The results of this model fit well with the results from the thermogravimetric analyzer (TGA) tests and, thus this model was used to study the characteristics of the SCS reaction. The SCS reaction consists of a mass-loss stage and a mass-growth stage, and the two stages are seperated by a minimum mass point. The mass-loss stage is dominated by the calcination of $\mathrm{CaCO}_{3}$, while the mass-growth stage is dominated by the sulfation of $\mathrm{CaO}$. The minimum mass point is a balance point of the mass change caused by the two reactions. The calcination reaction occurred in a layer of the particle. As the calcination reaction progresses, the reaction front moves inward and a $\mathrm{CaO}$ layer is formed. The $\mathrm{SO}_{2}$ in the calcination atmosphere can react with the $\mathrm{CaO}$ layer and produce $\mathrm{CaSO}_{4}$. The $\mathrm{CaSO}_{4}$ can fill the pores of the $\mathrm{CaO}$ layer and narrow the pore width, increase the $\mathrm{CO}_{2}$ diffusion resistance and consequently slow the calcination reaction. The sulfation reaction becomes slower as the reaction progresses. There was an upper limit to the sulfation conversion, which is much higher in the outer layer of the particle. For a typical particle with a radius of $200 \mu \mathrm{m}$, the sulfation reaction ceases in the inner part $(0-150 \mu \mathrm{m})$ of the particle due to the exhaustion of $\mathrm{SO}_{2}$, while in the outer part of the particle $(150-200 \mu \mathrm{m})$, the decrease of the sulfation rate is caused by the simultaneous decline of the reaction surface area, surface $\mathrm{Ca}^{2+}$ ion concentration and $\mathrm{SO}_{2}$ concentration.
\end{abstract}

Keywords: Limestone; Calcination; Sulfation; Random pore; Model; CFB

\section{Introduction}

Circulating fluidized bed (CFB) boilers have high combustion stability and a long residence time for fuels, and are suitable for combusting poor fuels like low-rank coals. With the industrial application of 600 MWe supercritical CFB boilers and the development of 1000 MWe boilers [1, 2], they are expected to be widely used for power generation in many countries.

In-situ desulfurization by limestone is one of the main advantages of CFB boilers. However, the low sulfur capture efficiency and low calcium utilization (typically less than 40\%) remain key limitations [3]. After decades of study, these problems are still unsolved. Effective ways to improve the desulfurization efficiency and calcium utilization in CFB boilers are still being sought.

To capture $\mathrm{SO}_{2}$, limestone will experience the calcination reaction (1) and the sulfation reaction (2):

$$
\begin{gathered}
\mathrm{CaCO}_{3} \rightarrow \mathrm{CaO}+\mathrm{CO}_{2} \\
\mathrm{CaO}+\mathrm{SO}_{2}+1 / 2 \mathrm{O}_{2} \rightarrow \mathrm{CaSO}_{4}
\end{gathered}
$$


In desulfurization studies, the calcination of limestone is usually assumed to finish effectively instantaneously [4]. Thus, past investigators usually considered the calcination and sulfation reactions to be independent of each other, and separated the calcination process from the sulfation and paid more attention to the sulfation of $\mathrm{CaO}$ [5-8]. However, although the calcination of limestone is much faster than the sulfation reaction, it still takes hundreds of seconds for limestone particles to decompose completely in CFBs [9]. Since the calcination occurs in flue gases containing $\mathrm{SO}_{2}$, $\mathrm{CaSO}_{4}$ can form in the particle simultaneously. The calcination reaction usually occurs from the particle surface to the deep interior of a typical sorbent particle, and the pores in the CaO layer serve as the diffusion path for $\mathrm{CO}_{2}$. Since the mole volume of $\mathrm{CaSO}_{4}$ is much larger than that of $\mathrm{CaO}$, the formed $\mathrm{CaSO}_{4}$ can fill or even block the pores of $\mathrm{CaO}$. If a pore is filled by $\mathrm{CaSO}_{4}$, the diffusion resistance of $\mathrm{CO}_{2}$ increases, and consequently the calcination rate of the particle will be reduced. If all the pores are blocked before complete decomposition, some $\mathrm{CaCO}_{3}$ will be sealed in the particle and remain undecomposed during the entire sulfation process [10].

The calcination and sulfation reactions occur simultaneously, and the two reactions can affect each other. We call this reaction process the 'simultaneous calcination/sulfation' (SCS) reaction of limestone and have carried out preliminary investigations on it in past studies [10, 11]. Our tests showed that the calcination rate of the SCS reaction is slower than that of the calcination without $\mathrm{SO}_{2}$, and the characteristics of the sulfation in the two reaction modes are also different [10].

Reaction models can help us understand the reaction mechanism. Many models have been put forward for the sulfation of $\mathrm{CaO}$, and they can be traced back to two basic types: the grain model [12] and the pore model [13]. Considering the structure change of the particle, investigators have modified their basic models. Based on the grain model, Hartman [14] took into account the loss of porosity caused by the formation of $\mathrm{CaSO}_{4}$; Georgakis et al. [15] considered the expansion of the grain and put forward the changing grain size model; Linder and Simonsson [16] noticed the sintering effect of $\mathrm{CaO}$ grains and produced a model assuming partially sintered spheres. Based on the pore model, Christman and Edgar [17] considered the pore size distribution and established the distributed pore size model; Bhatia and Perlmutter [18, 19] also considered the random overlap of the pores and developed the random pore model.

It should be noted that most of the models above only consider the sulfation of CaO. Only a few investigators noticed the interaction between the calcination and sulfation reaction. Mahuli et al. [20] took into account the calcination, sintering and sulfation simultaneously and established a modified grain-subgrain model. The model was used for the sulfation of limestone with small particle size $(<10 \mu \mathrm{m})$ at high temperature $\left(>900{ }^{\circ} \mathrm{C}\right)$, which does not represent the typical conditions in CFB boilers. Based on the single pore model, Keener et.al [21] put forward a model incorporating the concomitant calcination and sulfation reaction and found that they can affect each other. However, these models did not explore in detail the mechanism of the SCS reaction.

In this work, a new SCS reaction model based on the random pore model is established, which considers the calcination, sulfation and sintering of $\mathrm{CaO}$ together. To our knowledge, this is the first SCS reaction model based on the random pore concept. In this model, the characteristics of the SCS reaction are investigated, and attention is paid to the interaction between the calcination reaction and the sulfation reaction. The low calcium utilization in the sulfation reaction is also analyzed in detail. The findings of this work can enhance our knowledge of the reaction process of limestone in CFB boilers. 


\section{Model development}

\subsection{The random pore model}

The random pore model put forward by Bhatia and Perlmutter [18, 19] considered the pores of a particle as a set of randomly overlapped cylinders. The relationship between the pore surface area $S$ and pore volume $V$ can be described by

$$
\frac{S}{S_{0}}=\left(\frac{1-V}{1-V_{0}}\right) \sqrt{1-\psi \ln \left(\frac{1-V}{1-V_{0}}\right)}
$$

For reactions with product layers, like the calcination of $\mathrm{CaCO}_{3}$ and the sulfation of $\mathrm{CaO}$, formula (3) can also be used to describe the relationship between the reaction surface area and the volume enveloped by the reaction surface.

The structure parameter $\psi$ is determined by the initial pore structure of the particle. If the pores of a raw limestone particle are assumed to have a uniform pore size, then $\psi$ is determined on the initial porosity of the particle [22]

$$
\psi=-1 / \ln \left(1-\varepsilon_{0}\right)
$$

The random pore model has been used by Bhatia and Perlmutter [22] for the sulfation reaction of porous $\mathrm{CaO}$. The study of Khinast et al. [23] shows that the random pore model can also be used to describe the calcination of limestone particles. However, the random pore model for the SCS reaction of limestone has not been reported. In the following, the calcination model of limestone without $\mathrm{SO}_{2}$ is introduced first, then the SCS reaction model is established. Fig. 1(a) and 1(b) show the schematic of the random pore model for the calcination of limestone and the SCS reaction, respectively.

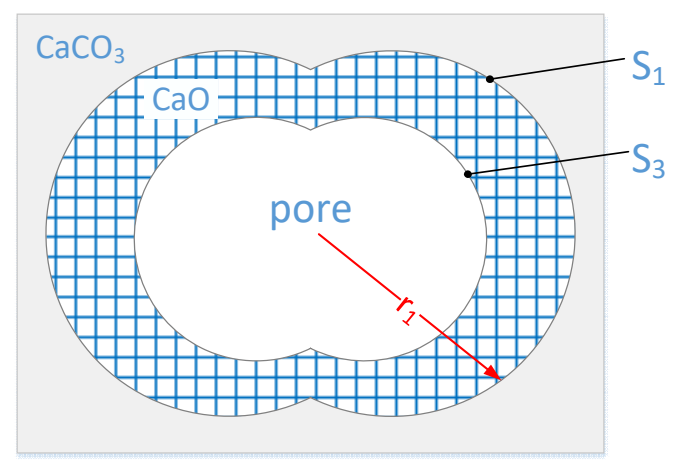

(a) Calcination of limestone without $\mathrm{SO}_{2}$

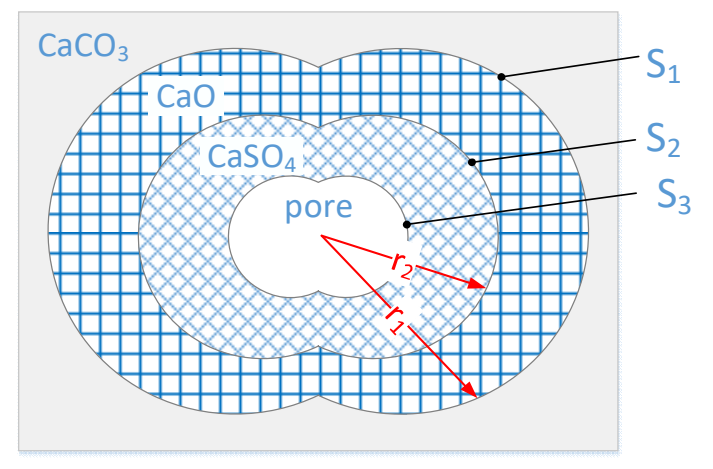

(b) The SCS reaction

Fig. 1 Schematic of the random pore model 


\subsection{The calcination of limestone particles without $\mathrm{SO}_{2}$}

First, we discuss the calcination of limestone particles under conditions without $\mathrm{SO}_{2}$. It is assumed that the particles maintain a uniform internal temperature distribution in the reaction process[21]. As shown in Fig. 1(a), the calcination reaction occurs on the surfaces between the $\mathrm{CaO}$ layer and the $\mathrm{CaCO}_{3}$ solid. The local calcination rate can be described by the moving speed of the calcination surface $S_{1}[21]$

$$
\frac{d r_{1}}{d t}=k_{1}\left(1-\frac{C_{\mathrm{i} 1}}{C_{e}}\right)
$$

The calcination conversion of $\mathrm{CaCO}_{3}$ can be described by

$$
\frac{d \alpha}{d t}=\frac{S_{1}}{1-\varepsilon_{0}} \frac{d r_{1}}{d t}=\frac{k_{1} S_{1}}{1-\varepsilon_{0}}\left(1-\frac{C_{\mathrm{i} 1}}{C_{e}}\right)
$$

2.2.1 Calcination reaction surface area $S_{1}$

The calcination conversion $\alpha$ can be related to $V_{1}$ (the volume enveloped by $S_{1}$ ) by

$$
1-\alpha=\frac{1-V_{1}}{1-V_{0}}
$$

Combining Eqs. (3) and (7), we obtain

$$
S_{1}=S_{0}(1-\alpha) \sqrt{1-\psi \ln (1-\alpha)}
$$

2.2.2 $\mathrm{CO}_{2}$ concentration on calcination reaction surface $C_{\mathrm{i} 1}$

The $\mathrm{CO}_{2}$ concentration at the calcination surface, $C_{\mathrm{i} 1}$, should be related to the $\mathrm{CO}_{2}$ concentration in the pore, $C_{1}$. The $\mathrm{CO}_{2}$ generated from the calcination surface $S_{1}$ first diffuses through the $\mathrm{CaO}$ layer to the pore, then diffuses through the pores to the outside of the particle. Assuming a linear concentration gradient of $\mathrm{CO}_{2}$ in the $\mathrm{CaO}$ layer, the material balance over $\mathrm{CO}_{2}$ provides [19]

$$
D_{p 1} \frac{C_{\mathrm{i} 1}-C_{1}}{\Delta_{1}}=\frac{k_{1}}{V_{\mathrm{CaCO}_{3}}^{M}}\left(1-\frac{C_{\mathrm{i} 1}}{\mathrm{C}_{\mathrm{e}}}\right)
$$

The mean thickness of the $\mathrm{CaO}$ layer $\Delta_{1}$ can be considered to be small in comparison to the dimensions of the calcination surface [23]; thus

$$
\frac{d \Delta_{1}}{d t}=Z_{1} \frac{d r_{1}}{d t}
$$

Combining Eqs. (6), (8) and (10), we get

$$
\frac{d \Delta_{1}}{d \alpha}=\frac{Z_{1}\left(1-\varepsilon_{0}\right)}{S_{0}(1-\alpha) \sqrt{1-\psi \ln (1-\alpha)}}
$$

which, upon integrating with $\Delta_{1}=0$ when $\alpha=0$, yields

$$
\Delta_{1}=\frac{2 Z_{1}\left(1-\varepsilon_{0}\right)}{\psi S_{0}}[\sqrt{1-\psi \ln (1-\alpha)}-1]
$$

Combining Eqs. (9) and (12) we get 


$$
1-\frac{C_{\mathrm{i} 1}}{\mathrm{C}_{\mathrm{e}}}=\frac{1-C_{1} / \mathrm{C}_{\mathrm{e}}}{1+\frac{\beta_{1} Z_{1}}{\psi}[\sqrt{1-\psi \ln (1-\alpha)}-1]}
$$

in which $\beta_{1}=\frac{2 k_{1}\left(1-\varepsilon_{0}\right)}{D_{p 1} S_{0} V_{\mathrm{CaCO}_{3}}^{M} C_{e}}$.

\subsection{The sulfation of $\mathrm{CaO}$ in the $\mathrm{SCS}$ reaction}

It has been shown that in the sulfation of $\mathrm{CaO}$, the $\mathrm{Ca}^{2+}$ diffused through the $\mathrm{CaSO}_{4}$ layer from the $\mathrm{CaO} / \mathrm{CaSO}_{4}$ interface to the $\mathrm{CaSO}_{4} /$ pore interface and reacted with the $\mathrm{SO}_{2}$ on the $\mathrm{CaSO}_{4}$ surface [24, 25]. Thus in Fig. 1(b), the sulfation reaction occurs on $S_{3}$, and the local sulfation rate $v_{\mathrm{s}}$ can be described by [20]

$$
v_{s}=k_{2} C_{2} C_{i o n}
$$

and the local sulfation conversion $X$ can be described by

$$
\frac{d X}{d t}=\frac{v_{s} S_{3}}{\left(1-\varepsilon_{0}\right) / V_{\mathrm{CaCO}_{3}}^{M}}=\frac{k_{2} C_{2} C_{i o n} S_{3}}{\left(1-\varepsilon_{0}\right) / V_{\mathrm{CaCO}_{3}}^{M}}
$$

2.3.1 Sulfation reaction surface area $S_{3}$

The sulfation reaction surface is the pore surface, thus

$$
\frac{S_{3}}{S_{0}}=\left(\frac{1-\varepsilon}{1-\varepsilon_{0}}\right) \sqrt{1-\psi \ln \left(\frac{1-\varepsilon}{1-\varepsilon_{0}}\right)}
$$

in which $\varepsilon$ is the local porosity. To include the sintering effect of $\mathrm{CaO}$ and $\mathrm{CaSO}_{4}$ on the loss of porosity, a logarithmic relation of sintering according to the study of Borgwardt [26] was used. Therefore, when the calcination reaction, sulfation reaction and the sintering effect are considered together, the local porosity $\varepsilon$ can be described by

$$
\frac{1-\varepsilon}{1-\varepsilon_{0}}=1-\left(1-\mathrm{Z}_{1}\right) \alpha+\mathrm{Z}_{1}\left(\mathrm{Z}_{2}-1\right) \mathrm{X}+\frac{k_{s} \ln \left(t-t_{0}\right)}{1-\varepsilon_{0}}
$$

The sintering rates of $\mathrm{CaO}$ and $\mathrm{CaSO}_{4}$ are assumed to be the same, and this assumption has also been used in the study of Milne et al. [27].

2.3.2 $\mathrm{Ca}^{2+}$ ion concentration on the sulfation reaction surface $C_{\text {ion }}$

Assuming a linear concentration gradient of $\mathrm{Ca}^{2+}$ in the $\mathrm{CaSO}_{4}$ layer, the material balance over $\mathrm{Ca}^{2+}$ gives

$$
D_{p 2 s} \frac{C_{i o n}^{0}-C_{i o n}}{\Delta_{2}}=v_{s}
$$

Combining Eqs. (14) and (18) yields

$$
C_{i o n}=\frac{C_{i o n}^{0}}{1+\left(k_{2} \Delta_{2} C_{2} / D_{p 2 s}\right)}
$$

The mean thickness of the $\mathrm{CaSO}_{4}$ layer $\Delta_{2}$ can be considered to be small in comparison to the dimensions of the surface $S_{2}$, thus 


$$
\frac{d \Delta_{2}}{d t}=Z_{2} \frac{d r_{2}}{d t}
$$

The sulfation conversion can also be described by

$$
\frac{d X}{d t}=\frac{S_{2}}{Z_{1}\left(1-\varepsilon_{0}\right)} \frac{d r_{2}}{d t}
$$

Eqs. (21) divided by (20) yields

$$
\frac{d \Delta_{2}}{d X}=\frac{Z_{2} Z_{1}\left(1-\varepsilon_{0}\right)}{S_{2}}
$$

in which $S_{2}$ can be calculated according to Eq. (3)

$$
\frac{S_{2}}{S_{0}}=\left(\frac{1-V_{2}}{1-\varepsilon_{0}}\right) \sqrt{1-\psi \ln \left(\frac{1-V_{2}}{1-\varepsilon_{0}}\right)}
$$

and $V_{2}$ is the volume enveloped by $S_{2}$

$$
\frac{1-V_{2}}{1-\varepsilon_{0}}=1-\left(1-Z_{1}\right) \alpha-Z_{1} X+\frac{k_{\mathrm{s}} \ln \left(t-t_{0}\right)}{1-\varepsilon_{0}}
$$

Integrating Eq. (22) with $\Delta_{2}=0$ when $X=0$, we get

$$
\Delta_{2}=\frac{2 Z_{2}\left(1-\varepsilon_{0}\right)}{\psi S_{0}}\left(\sqrt{1-\psi \ln g_{1}}-\sqrt{1-\psi \ln g_{2}}\right)
$$

in which $g_{1}=1-\left(1-\mathrm{Z}_{1}\right) \alpha-\mathrm{Z}_{1} \mathrm{X}+\frac{k_{\mathrm{s}} \ln \left(t-t_{0}\right)}{1-\varepsilon_{0}} ; g_{2}=1-\left(1-\mathrm{Z}_{1}\right) \alpha+\frac{k_{\mathrm{s}} \ln \left(t-t_{0}\right)}{1-\varepsilon_{0}}$.

\subsection{The calcination reaction in the SCS reaction}

As shown in Fig. 1(b), compared with the calcination of $\mathrm{CaCO}_{3}$ in an atmosphere without $\mathrm{SO}_{2}$ (Fig. 1(a)), a layer of $\mathrm{CaSO}_{4}$ formed, so the thickness of $\mathrm{CaO}$ became $\Delta_{1}^{\prime}$

$$
\Delta_{1}^{\prime}=\Delta_{1}-\left(\Delta_{2} / Z_{2}\right)
$$

The diffusion of $\mathrm{CO}_{2}$ through the $\mathrm{CaO}$ and $\mathrm{CaSO}_{4}$ layer can be described by

$$
\frac{C_{\mathrm{i} 1}-C_{1}}{\Delta_{1}^{\prime} / D_{p 1}-\Delta_{2} / D_{p 2 c}}=\frac{k_{1}}{V_{\mathrm{CaCO}_{3}}^{M}}\left(1-\frac{C_{\mathrm{i} 1}}{C_{e}}\right)
$$

From Eq. (27) we get

$$
1-\frac{C_{\mathrm{i} 1}}{C_{e}}=\frac{1-C_{1} / C_{e}}{1+u}
$$

in which $u=\frac{k_{1}\left[\Delta_{1}+\Delta_{2}\left(D_{p 1} / D_{p 2 c}-1 / Z_{2}\right)\right]}{D_{\mathrm{p} 1} C_{e} V_{C a C O_{3}}^{M}}$

\subsection{Diffusion of reaction gases in pore}

Based on the pseudo-steady state hypothesis[20], the diffusion of $\mathrm{CO}_{2}$ in the pores of the particle can be described by 


$$
\frac{1}{R^{2}} \frac{\partial}{\partial R}\left(D_{\mathrm{el}} R^{2} \frac{\partial C_{1}}{\partial R}\right)=-\frac{\left(1-\varepsilon_{0}\right)}{V_{\mathrm{CaCO}_{3}}^{M}} \frac{d \alpha}{d t}
$$

with boundary conditions

$\begin{array}{ll}\frac{\partial C_{1}}{\partial R}=0, & R=0 \\ C_{1}=C_{1 b}, & R=R_{0} ;\end{array}$

Similarly, the diffusion of $\mathrm{SO}_{2}$ in the pore can be described as

$$
\frac{1}{R^{2}} \frac{\partial}{\partial R}\left(D_{e 2} R^{2} \frac{\partial C_{2}}{\partial R}\right)=\frac{\left(1-\varepsilon_{0}\right)}{V_{\mathrm{CaCO}_{3}}^{M}} \frac{d X}{d t}
$$

with boundary conditions

$$
\begin{aligned}
& \frac{\partial C_{2}}{\partial R}=0, \quad R=0 ; \\
& C_{2}=C_{2 b}, \quad R=R_{0} ;
\end{aligned}
$$

The Knudsen diffusion is the main pattern of diffusion of $\mathrm{CO}_{2}$ in porous $\mathrm{CaO}$ [28]. The Knudsen diffusion coefficient can be calculated by [29]

$$
D_{\mathrm{K}, \mathrm{CO}_{2}}=97 r_{a} \sqrt{T / M_{\mathrm{CO}_{2}}}
$$

in which $r_{\mathrm{a}}$ is the mean pore radius, and can be calculated by [30]

$$
r_{a}=2 \varepsilon / S_{3}
$$

Thus, the effective diffusion coefficient of $\mathrm{CO}_{2}$ can be related to the Knudsen diffusion coefficient by [31]

$$
D_{\mathrm{e} 1}=\varepsilon^{2} D_{\mathrm{K}, \mathrm{CO}_{2}}
$$

The effective diffusivity of $\mathrm{SO}_{2}$ in the pore, $D_{\mathrm{e} 2}$, can be calculated in a method similar to that used to calculate $D_{\mathrm{e} 1}$.

\subsection{Gas diffusion coefficient in $\mathrm{CaO}$ and $\mathrm{CaSO}_{4}$ product layer}

According to the study of Borgwardt [26], the initial surface area of nascent $\mathrm{CaO}$ has surface area of $104 \mathrm{~m}^{2} / \mathrm{g}$ and porosity of 0.54 , which correspond to a mean pore radius of $6.8 \mathrm{~nm}$ according to formula (32). The study of Milne et al. [27] showed that in the sintering of $\mathrm{CaO}$ product layer, the surface area of $\mathrm{CaO}$ changed linearly with porosity, thus the pore radius of the product $\mathrm{CaO}$ remains unchanged. To calculate the $\mathrm{CO}_{2}$ diffusion coefficient in $\mathrm{CaO}$ product layer $D_{\mathrm{p} 1}$, a residual porosity of $2.5 \%$ was used [27]. The $\mathrm{CO}_{2}$ diffusion coefficient in $\mathrm{CaSO}_{4}$ product layer $D_{\mathrm{p} 2 \mathrm{c}}$, is assumed to be the same as $D_{\mathrm{p} 1}$ for the convenience of model solving.

\section{Model verification}

\subsection{Experimental test}

In our previous work [10], the SCS reaction was tested by thermogravimetric analyzer (TGA). The test results were used to verify the model in this work. The limestone sample is in the size range of 0.25-0.425 $\mathrm{mm}$ and contains $95 \% \mathrm{CaCO}_{3}$. To test the SCS reaction, an approximately $20 \mathrm{mg}$ sample 
was loaded in the sample pan, and the TGA was flushed by $\mathrm{CO}_{2}$ before heating began. The limestone was then heated to $850^{\circ} \mathrm{C}$ in pure $\mathrm{CO}_{2}$. Once the temperature was reached, the TGA gas supply was switched to synthetic flue gas containing $15 \% \mathrm{CO}_{2}, 3 \% \mathrm{O}_{2}, 0.38 \% \mathrm{SO}_{2}$ and balance $\mathrm{N}_{2}$. The flow rate of $100 \mathrm{~mL} / \mathrm{min}$ was used throughout the test. This flow rate was not a rate-limiting factor as had been verified elsewhere [10]. In order to test the calcination-then-sulfation reaction, the sample was first heated in pure $\mathrm{CO}_{2}$ and, once the temperature reached $850^{\circ} \mathrm{C}$, the gas was switched to pure $\mathrm{N}_{2}$ to calcine the sample. When the calcination of sample was completed, the gas was switched to the synthetic flue gas containing $\mathrm{SO}_{2}$ for the sulfation of the $\mathrm{CaO}$.

\subsection{Model solution and verification}

The model established above involves coupled equations of chemical reactions and material transport and, thus it has to be solved numerically. The limestone particle was simplified to a sphere with $0.4 \mathrm{~mm}$ diameter. The initial porosity $\varepsilon_{0}$ is 0.005 , and the initial pore surface area is $1.66 \mathrm{~m}^{2} / \mathrm{g}$, which are measured by the $\mathrm{N}_{2}$ adsorption method (Micromeritics TriStar II 3020) [32]. The key parameters used in the model are listed in Table 1 , while the other parameters, $k_{1}, k_{2}, k_{\mathrm{s}}$ and $D_{\mathrm{p} 2 \mathrm{~s}}$, were obtained from the best fit of experimental data.

Table 1 Model parameters

\begin{tabular}{ll}
\hline parameter & value \\
\hline$k_{1} /\left(\mathrm{m} \mathrm{s}^{-1}\right)$ & $1.75 \times 10^{-9}$ \\
$k_{2} /\left(\mathrm{m}^{4} \mathrm{~mol}^{-1} \mathrm{~s}^{-1}\right)$ & $2.5 \times 10^{-9}$ \\
$k_{\mathrm{s}}$ & 0.0125 \\
$D_{\mathrm{p} 2 \mathrm{~s}} /\left(\mathrm{m}^{2} \mathrm{~s}^{-1}\right)$ & $2.25 \times 10^{-20}$ \\
\hline
\end{tabular}

The sample mass in both the SCS reaction and the calcination-then-sulfation reaction obtained experimentally were compared with those from the model calculation, as shown in Fig. 2.

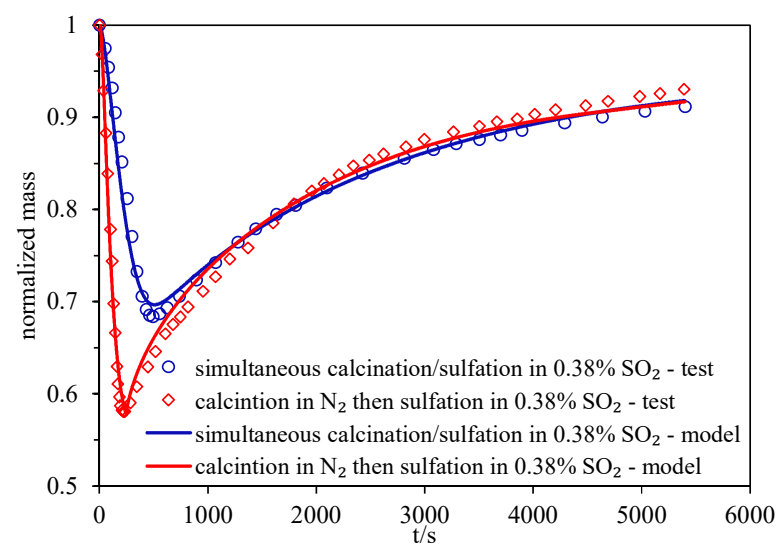

Fig. 2 Comparison of model results and test results

As shown in Fig 2, the model results fit well with the experimental data for both reaction patterns. Therefore, the above model and parameters in Table 1 are accurate enough to describe the process of the SCS reaction and the calcination-then-sulfation reaction of limestone particles.

Since in the SCS reaction, the fraction of $\mathrm{CaCO}_{3}, \mathrm{CaO}$ and $\mathrm{CaSO}_{4}$ change simultaneously, it is difficult to know the calcination ratio or sulfation ratio from the weight data of the TGA. Thus, the calcination and sulfation characteristics of the SCS reaction were investigated mainly based on the model results in this work. 


\section{Results and Discussion}

\subsection{Characteristics of the SCS reaction}

First the characteristics of the SCS reaction were investigated. The sample mass of the SCS reaction under different $\mathrm{SO}_{2}$ concentrations are shown in Fig. 3(a), compared to the calcination without $\mathrm{SO}_{2}$; the molar fraction of $\mathrm{CaO}, \mathrm{CaCO}_{3}$ and $\mathrm{CaSO}_{4}$ in the $\mathrm{SCS}$ reaction are shown in Fig. $3(b)$.

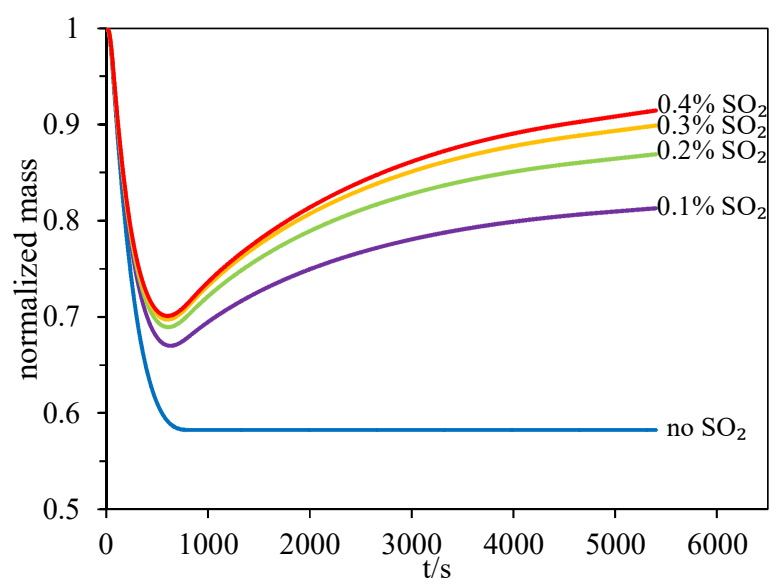

(a) Sample mass

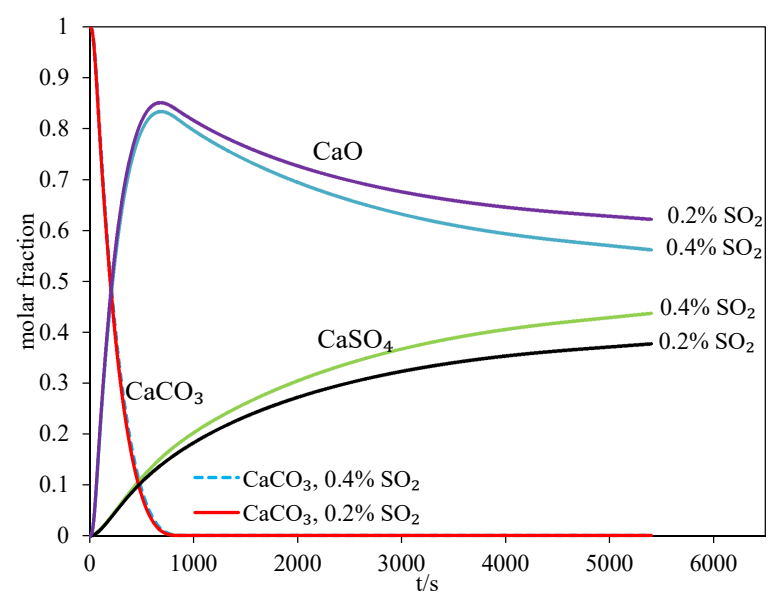

(b) Molar fraction of $\mathrm{CaO}, \mathrm{CaCO}_{3}$ and $\mathrm{CaSO}_{4}$

Fig. 3 Characteristics of the simultaneous calcination/sulfation reaction

As shown in Fig. 3(a), under condition without $\mathrm{SO}_{2}$, the sample mass decreased to 0.58 then remained unchanged. Since no $\mathrm{SO}_{2}$ was present, only calcination of $\mathrm{CaCO}_{3}$ occurred under this condition. While under conditions with $\mathrm{SO}_{2}$, the sample demonstrated a quick mass-loss stage first, followed by a slow mass-increase stage. Obviously, the mass loss is caused by $\mathrm{CaCO}_{3}$ decomposition, and the mass growth is a result of $\mathrm{CaO}$ sulfation. There is a minimum mass point for the SCS reaction, which is determined by the mass balance of $\mathrm{CaCO}_{3}$ calcination and $\mathrm{CaO}$ sulfation. The minimum mass point under $0.4 \% \mathrm{SO}_{2}$ is 0.7 , much higher than the 0.58 for calcination without $\mathrm{SO}_{2}$.

Fig. 3(b) demonstrates the change of the mole fraction of $\mathrm{CaO}, \mathrm{CaCO}_{3}$ and $\mathrm{CaSO}_{4}$ in the SCS reaction. It can be seen that the amount of $\mathrm{CaSO}_{4}$ increased monotonically, while the amount of $\mathrm{CaO}$ increased first, then decreased. At about $800 \mathrm{~s}$, the calcination reaction was complete, when the molar fraction of $\mathrm{CaSO}_{4}$ was as high as $15 \%$ (for condition with $0.4 \% \mathrm{SO}_{2}$ ). This means that the sulfation reaction occurred in the calcination stage. The formed $\mathrm{CaSO}_{4}$ in the calcination stage made 
the minimum mass point rise from 0.58 under condition without $\mathrm{SO}_{2}$ to about 0.7 under condition of $0.4 \% \mathrm{SO}_{2}$.

As shown in Fig. 3, a higher concentration of $\mathrm{SO}_{2}$ would increase the sulfation rate, which in consequence leads to a higher minimum mass point and a higher final sulfation conversion. Although the molar fraction of $\mathrm{CaSO}_{4}$ continued to increase, the sulfation rate declined gradually. Fig. 4 shows the change of the sulfation rate.

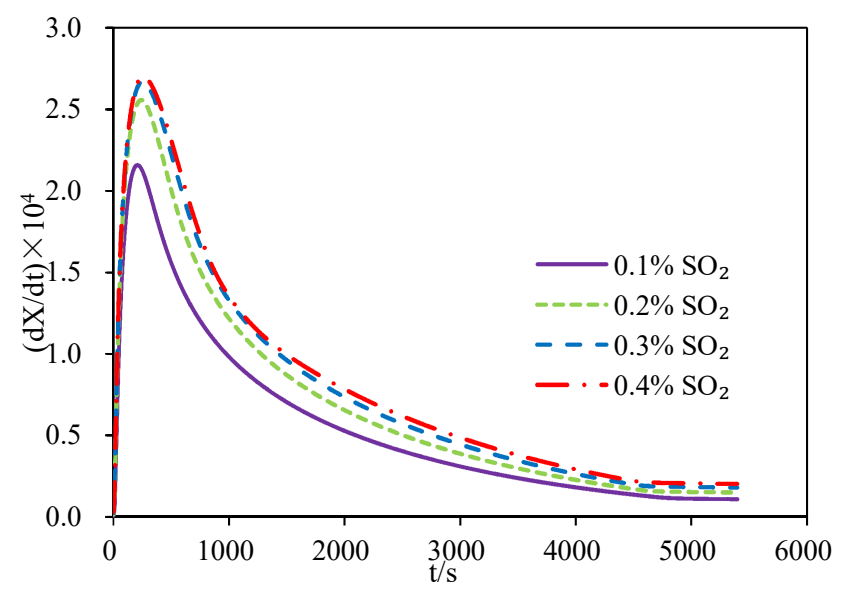

Fig. 4 Sulfation rate in the SCS reaction

From Fig. 4, the sulfation reaction rate rapidly increased initially, reached a peak value, then decreased gradually. Taking the condition with $0.4 \% \mathrm{SO}_{2}$ for example, its sulfation rate after $5000 \mathrm{~s}$ was less than $10 \%$ of the peak value. The fast rise of sulfation rate is due to the increasing $\mathrm{CaO}$ amount from the calcination reaction, which increases the sulfation reaction surface area. The decrease of the sulfation rate, which is caused by complex factors, will be discussed later in detail.

\subsection{Calcination reaction of the SCS reaction}

As speculated above, the sulfation reaction may affect the calcination reaction. To study the effect of $\mathrm{SO}_{2}$ on the calcination reaction, the calcination ratio under $0.4 \% \mathrm{SO}_{2}$ was compared with that under no $\mathrm{SO}_{2}$, as shown in Fig. 5.

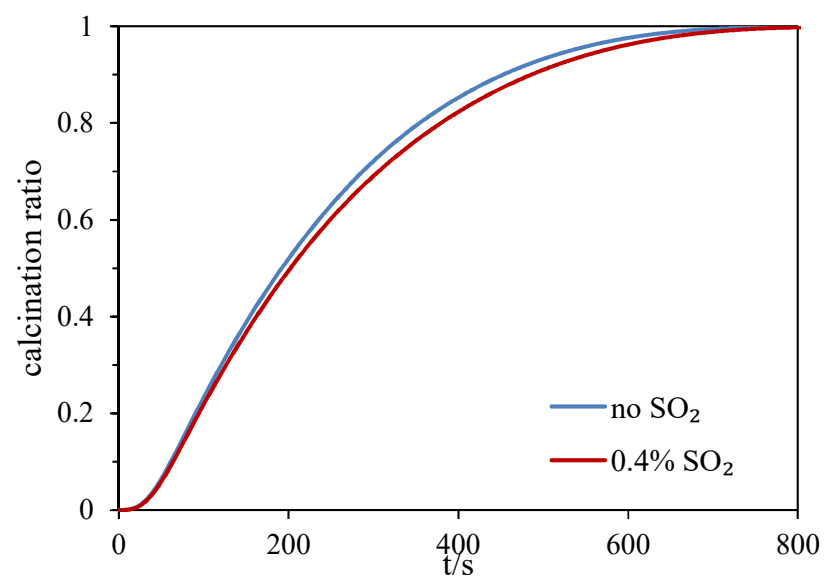

Fig. 5 Effect of $\mathrm{SO}_{2}$ on calcination of limestone

In Fig. 5, compared with the calcination reaction under the condition without $\mathrm{SO}_{2}$, the calcination under $0.4 \% \mathrm{SO}_{2}$ was relatively slower, which means that $\mathrm{SO}_{2}$ retarded the calcination reaction. To deeply understand the effect of $\mathrm{SO}_{2}$ on the calcination process, the distribution of calcination ratio 
and calcination rate at $300 \mathrm{~s}, 500 \mathrm{~s}$ and $700 \mathrm{~s}$ under different $\mathrm{SO}_{2}$ concentrations $(0.2 \%$ and $0.4 \%)$ were calculated and compared with results without $\mathrm{SO}_{2}$, as shown in Fig. 6.

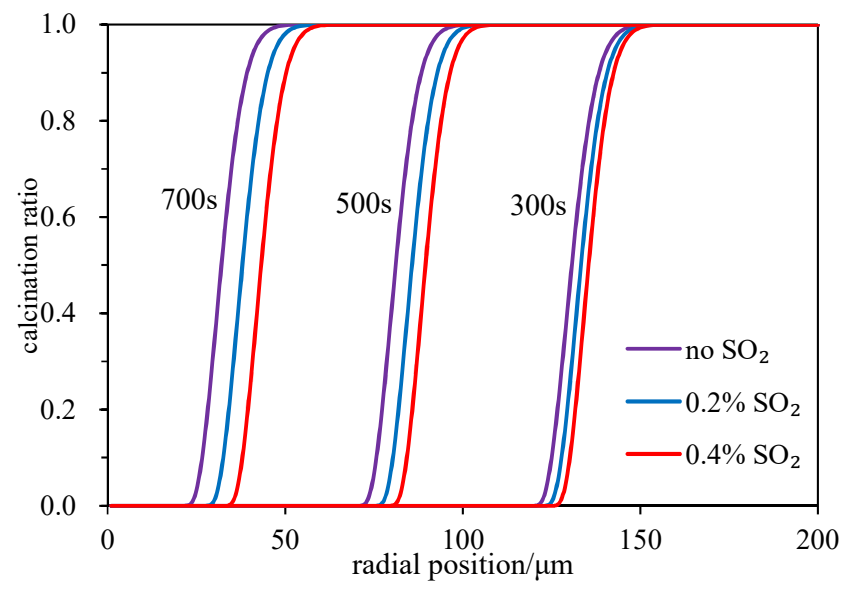

Fig. 6 Effect of $\mathrm{SO}_{2}$ on the distribution of calcination ratio

First, Fig. 6 shows the dynamic process of the calcination of a limestone particle. The calcination reaction occurs in a thin layer of the particle, not in the whole particle or on a sharp surface. As calcination progressed, the calcination layer moved inward, producing a $\mathrm{CaO}$ product layer on the outside of the particle. This means that the calcination of the limestone particle was described more properly by the zone reaction model than the homogeneous reaction model or the unreacted core shrinking model, according to the study of Wen [33].

Second, the $\mathrm{SO}_{2}$ in the calcination atmosphere slowed the moving speed of the calcination layer, as shown in Fig. 6. Under higher $\mathrm{SO}_{2}$ concentration, the calcination layer fell further behind. This means that the $\mathrm{SO}_{2}$ decreased the local calcination rate. The most probable reason for this phenomenon is that when limestone was calcined in an atmosphere containing $\mathrm{SO}_{2}, \mathrm{CaSO}_{4}$ formed in the $\mathrm{CaO}$ layer and increased the transfer resistance of $\mathrm{CO}_{2}$. To demonstrate this, the effective diffusion coefficient of $\mathrm{CO}_{2}$ in the pores of the $\mathrm{CaO}$ layer was calculated in Fig. 7.

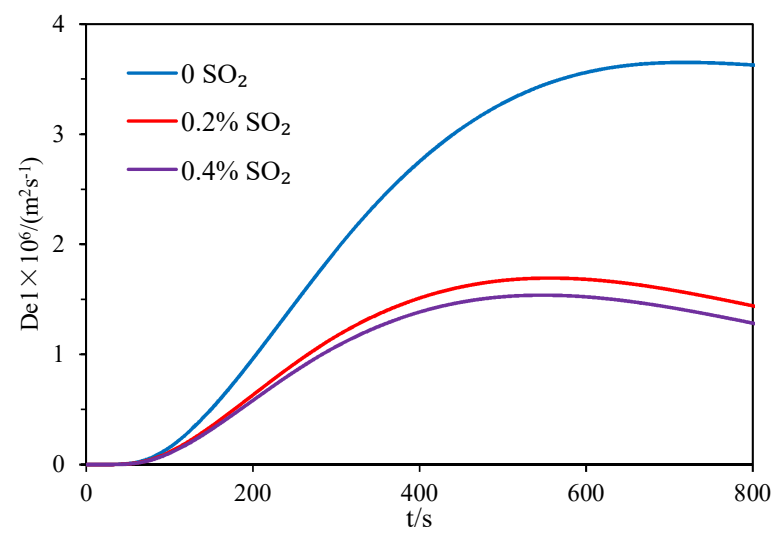

Fig. 7 Effect of $\mathrm{SO}_{2}$ on the effective diffusion coefficient of $\mathrm{CO}_{2}$ in pore

As shown in Fig. 7, the effective diffusion coefficient of $\mathrm{CO}_{2}, D_{\mathrm{el}}$, was lower under the condition with $\mathrm{SO}_{2}$ than that without $\mathrm{SO}_{2}$, and the higher the $\mathrm{SO}_{2}$ concentration became, $D_{\mathrm{e} 1}$ decreased further. A lower diffusion coefficient means higher diffusion resistance, which can increase the $\mathrm{CO}_{2}$ concentration on the calcination site, in consequence decreasing the calcination rate.

\subsection{The sulfation reaction of the SCS reaction}

According to Eq. (2), the sulfation conversion of calcium can be as high as $\sim 100 \%$ theoretically; 
however, considering the limitation of pore space to the growth of $\mathrm{CaSO}_{4}$, the calcium conversion is limited to $69 \%$. However, the Ca utilization in an actual CFB is usually lower than $40 \%$ [3]. Under typical conditions of $0.4 \% \mathrm{SO}_{2}$ with $0.4 \mathrm{~mm}$ limestone particles in Fig. 3(b), the calcium utilization is about $42 \%$ after $90 \mathrm{~min}$ of reaction. To know why the sulfation rate slows down and the calcium utilization cannot reach the theoretical value, the distribution of sulfation ratio and sulfation rate were calculated under condition of $0.4 \% \mathrm{SO}_{2}$ with $0.4 \mathrm{~mm}$ particles, as shown in Fig. 8.

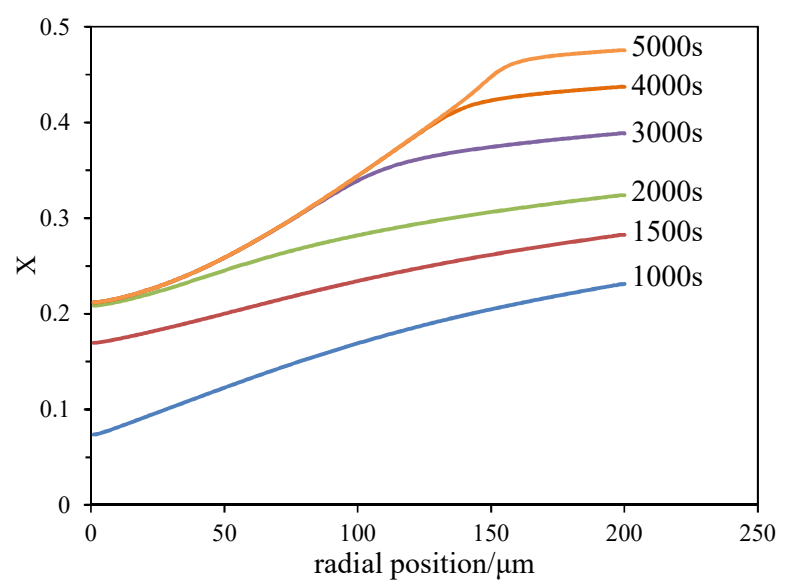

(a) Distribution of sulfation ratio

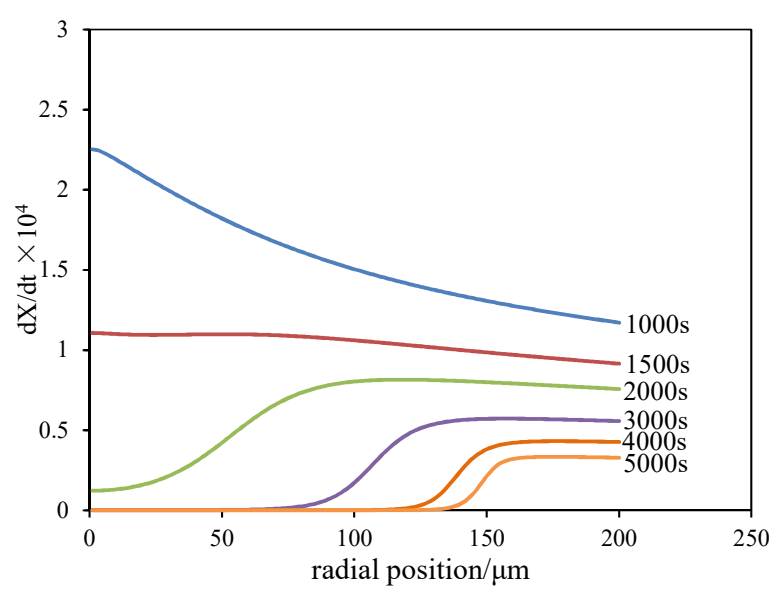

(b) Distribution of sulfation rate

Fig. 8 Distribution of sulfation ratio and sulfation rate

From Fig. 8(a), the sulfation conversion increased with reaction time, but there was an upper limit to it. The conversion at the particle center first reached the upper limit. In the outer layer of the particle, the upper limit was much higher, and the time to reach it was much longer. At the surface of the particle, the sulfation conversion was about $45 \%$ at $5000 \mathrm{~s}$, and the sulfation reaction continued, while in the core of the particle, the sulfation conversion reached the upper limit of $20 \%$ as early as 2000 s. Fig. 8(b) shows the sulfation rate; as the reaction progressed, the sulfation rate in the whole particle decreased, but it decreased faster in the inner layer of the particle. After $2000 \mathrm{~s}$, more and more inner area of the particle experienced the cessation of the sulfation reaction. At $5000 \mathrm{~s}$, the sulfation reaction in almost all of the $0-150 \mu \mathrm{m}$ part of the particle stopped. On the surface of the particle, the sulfation rate reduced by $70 \%$, from $1.17 \times 10^{-4} / \mathrm{s}$ at $1000 \mathrm{~s}$ to $0.33 \times 10^{-4} / \mathrm{s}$ at $5000 \mathrm{~s}$.

According to the sulfation rate formula (15), there were three key factors that affect the sulfation rate: the sulfation reaction surface area; the $\mathrm{Ca}^{2+}$ ion concentration; and the $\mathrm{SO}_{2}$ concentration on the sulfation surface. To know why there is an upper limit to the sulfation conversion and why the 
sulfation rate decreased, the changes of these three parameters were calculated, as shown in Figs. 9, 10 and 11 , respectively.

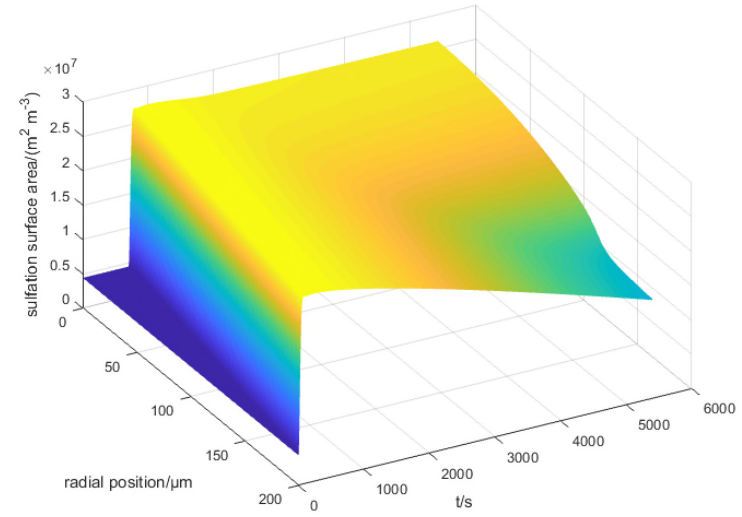

Fig. 9 Surface area for the sulfation reaction

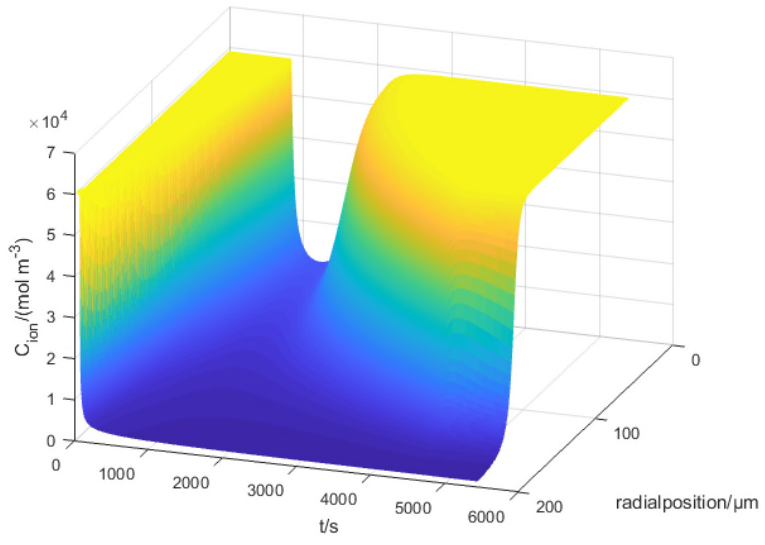

Fig. $10 \mathrm{Ca}^{2+}$ ion concentration on the sulfation surface

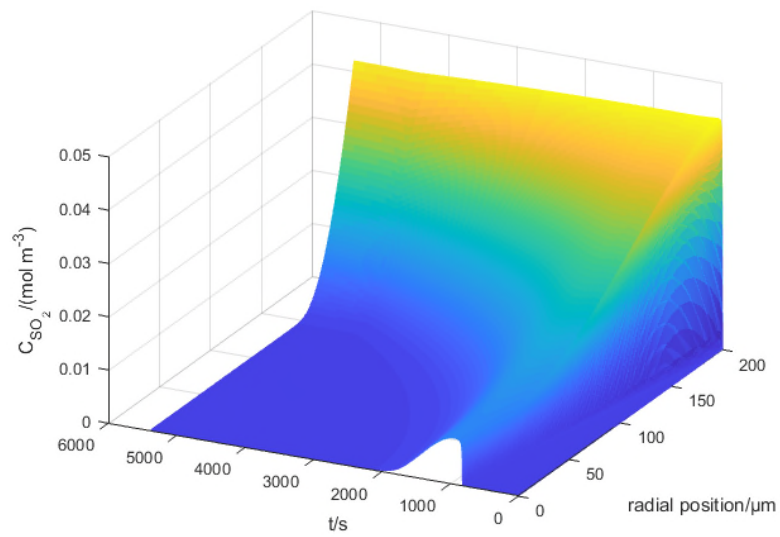

Fig. $11 \mathrm{SO}_{2}$ concentration on the sulfation surface

Fig. 9 shows that the surface area of sulfation reaction increased to a peak value first, then decreased gradually. The surface area of sulfation in the outer part of the particle decreased faster than that in the core of the particle. With reaction proceeding from $1000 \mathrm{~s}$ to $5000 \mathrm{~s}$, the surface area of sulfation in the 150-200 $\mu \mathrm{m}$ layer decreased by $40 \%$, while in the core of the particle it reduced by only $4 \%$.

Fig. 10 shows that in the $150-200 \mu \mathrm{m}$ layer of the particle, the $\mathrm{Ca}^{2+}$ ion concentration on the 
sulfation reaction surface decreased rapidly with time and remained at a low level. But it still decreased by about half from $1000 \mathrm{~s}$ to $5000 \mathrm{~s}$, which should be due to the growth of the $\mathrm{CaSO}_{4}$ product layer. In the $0-150 \mu \mathrm{m}$ layer of the particle, the $\mathrm{Ca}^{2+}$ ion concentration decreased first then increased. At $5000 \mathrm{~s}$, the surface $\mathrm{Ca}^{2+}$ ion concentration in the $0-150 \mu \mathrm{m}$ layer returned to the initial value. The change of the surface $\mathrm{Ca}^{2+}$ ion concentration was similar to that found by Mahuli [20] using the grain-subgrain model.

From Fig. 11, the $\mathrm{SO}_{2}$ concentration in the particle increased first and then decreases. But in the entire reaction period, the $\mathrm{SO}_{2}$ concentration in the outer layer of the particle was much higher than that in the inner layer. In the inner part of the particle, there was a zone where the $\mathrm{SO}_{2}$ was totally exhausted, and the $\mathrm{SO}_{2}$-exhausted zone became larger as the reaction progressed. After $5000 \mathrm{~s}$, the $\mathrm{SO}_{2}$ in nearly all the $0-150 \mu \mathrm{m}$ part of the particle was exhausted.

Combining Figs. 9, 10 and 11, the decrease of the sulfation rate and the upper limit of the sulfation conversion in Fig. 8 can be explained. The cessation of the sulfation reaction in the inner part (0-150 $\mu \mathrm{m})$ of the particle is mainly due to the exhaustion of $\mathrm{SO}_{2}$. Since the $\mathrm{SO}_{2}$-exhausted zone became larger as reaction progressed, the sulfation reaction in more and more area ceased, thus reaching the conversion upper limit. In the outer part (150-200 $\mu \mathrm{m})$, the decreased sulfation rate should be caused by the simultaneous decline of the reaction surface area, surface $\mathrm{Ca}^{2+}$ concentration and $\mathrm{SO}_{2}$ concentration.

The decrease of the $\mathrm{SO}_{2}$ concentration in the particle should be due to the decrease of the diffusion coefficient of $\mathrm{SO}_{2}$ in the pore of the particle, $D_{\mathrm{e} 2}$, which is shown in Fig. 12.

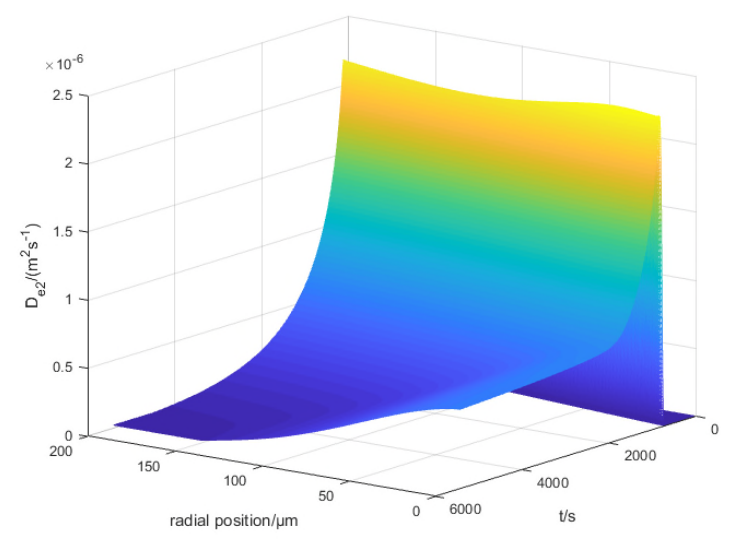

Fig. 12 The effective diffusion coefficient of $\mathrm{SO}_{2}$ in pore of the particle

As shown in Fig. 12, the diffusion coefficient of $\mathrm{SO}_{2}$ declined significantly as the reaction progressed. The diffusion coefficient of $\mathrm{SO}_{2}$ in the outer layer of the particle decreased faster than that in the inner part of the particle, which is consistent with the distribution of sulfation conversion in Fig. 8(a). The accumulation of $\mathrm{CaSO}_{4}$ in the pore decreased the porosity and narrowed the pore width, which decreased the diffusion coefficient of $\mathrm{SO}_{2}$, and consequently the $\mathrm{SO}_{2}$ concentration in the particle declined.

\section{Conclusions}

The SCS reaction is the real reaction process for limestone under CFB conditions. A random pore model, which considered the calcination of $\mathrm{CaCO}_{3}$, the sintering of $\mathrm{CaO}$ and the sulfation of $\mathrm{CaO}$ simultaneously, was established. The results of the model match well with the results from the TGA test. Based on the model, the characteristics of the SCS reaction were investigated, and the following conclusions can be drawn: 
(1) The SCS reaction has a mass-loss stage followed by a mass-growth stage. These two stages were divided by a minimum-mass point. The mass loss of particles was caused by the decomposition, while the mass growth was a result of the sulfation of $\mathrm{CaO}$.

(2) The calcination of limestone particles occurred in an inward-moving layer of the particle, thus the calcination reaction was more properly described by the zone reaction model, rather than the homogeneous reaction model or the unreacted-core shrinking model.

(3) $\mathrm{The} \mathrm{SO}_{2}$ in the calcination atmosphere can react with the $\mathrm{CaO}$ layer and form $\mathrm{CaSO}_{4}$, which can fill the pore of the $\mathrm{CaO}$ layer and narrow the pore width, increase the $\mathrm{CO}_{2}$ diffusion resistance and slow the calcination reaction.

(4) The sulfation reaction became slower as the reaction progressed. In the inner part of the particle the sulfation reaction ceased early because the $\mathrm{SO}_{2}$ was exhausted. With the sulfation reaction proceeding, more $\mathrm{CaSO}_{4}$ accumulated in the outer layer of the particle, which increased the diffusion resistance of $\mathrm{SO}_{2}$, leading to a larger $\mathrm{SO}_{2}$-exhausted zone. In the outer part of the particle, the decrease of the sulfation rate appears to be caused by the simultaneous decline of the reaction surface area, surface $\mathrm{Ca}^{2+}$ concentration and $\mathrm{SO}_{2}$ concentration.

\section{Acknowledgement}

This work was supported by the National Natural Science Foundation of China [51976059], and the Fundamental Research Funds for the Central Universities [2018ZD03].

\section{Notation}

\begin{tabular}{|c|c|}
\hline$C_{\mathrm{i} 1}$ & $\begin{array}{l}\mathrm{CO}_{2} \text { concentration on the calcination reaction site, } \mathrm{mol} / \mathrm{m}^{3} \\
\text { equilibrium } \mathrm{CO}_{2} \text { concentration of } \mathrm{CaCO}_{3} \text { decomposition } \mathrm{mol} / \mathrm{m}^{3}\end{array}$ \\
\hline$C_{\mathrm{e}}$ & equilibrium $\mathrm{CO}_{2}$ concentration of $\mathrm{CaCO}_{3}$ decomposition, $\mathrm{mol} / \mathrm{m}^{3}$ \\
\hline$C_{\text {ion }}$ & $\mathrm{Ca}^{2+}$ ion concentration on sulfation reaction site, $\mathrm{mol} / \mathrm{m}^{3}$ \\
\hline$C_{i o n}^{0}$ & $\mathrm{Ca}^{2+}$ ion concentration of $\mathrm{CaO}, \mathrm{mol} / \mathrm{m}^{3}$ \\
\hline$C_{1}$ & $\mathrm{CO}_{2}$ concentration in pore, $\mathrm{mol} / \mathrm{m}^{3}$ \\
\hline$C_{2}$ & $\mathrm{SO}_{2}$ concentration in pore, $\mathrm{mol} / \mathrm{m}^{3}$ \\
\hline$C_{1 \mathrm{~b}}$ & $\mathrm{CO}_{2}$ concentration in bulk flue gas, $\mathrm{mol} / \mathrm{m}^{3}$ \\
\hline$C_{2 b}$ & $\mathrm{SO}_{2}$ concentration in bulk flue gas, $\mathrm{mol} / \mathrm{m}^{3}$ \\
\hline$D_{\mathrm{p} 1}$ & $\mathrm{CO}_{2}$ diffusion coefficient in $\mathrm{CaO}$ layer, $\mathrm{m}^{2} / \mathrm{s}$ \\
\hline$D_{\mathrm{p} 2 \mathrm{c}}$ & $\mathrm{CO}_{2}$ diffusion coefficient in $\mathrm{CaSO}_{4}$ layer, $\mathrm{m}^{2} / \mathrm{s}$ \\
\hline$D_{\mathrm{p} 2 \mathrm{~s}}$ & $\mathrm{Ca}^{2+}$ ion diffusion coefficient in $\mathrm{CaSO}_{4}$ layer, $\mathrm{m}^{2} / \mathrm{s}$ \\
\hline$D_{\mathrm{k}, \mathrm{CO} 2}$ & Knudsen diffusion coefficient of $\mathrm{CO}_{2}$ in pore, $\mathrm{m}^{2} / \mathrm{s}$ \\
\hline$D_{\mathrm{e} 1}$ & effective diffusion coefficient of $\mathrm{CO}_{2}$ in pore, $\mathrm{m}^{2} / \mathrm{s}$ \\
\hline$D_{\mathrm{e} 2}$ & effective diffusion coefficient of $\mathrm{SO}_{2}$ in pore, $\mathrm{m}^{2} / \mathrm{s}$ \\
\hline$k_{1}$ & reaction rate constant of $\mathrm{CaCO}_{3}$ decomposition, $\mathrm{m} / \mathrm{s}$ \\
\hline$k_{2}$ & reaction rate constant of $\mathrm{CaO}$ sulfation, $\mathrm{m}^{4} /(\mathrm{mol} \cdot \mathrm{s})$ \\
\hline$k_{\mathrm{S}}$ & rate constant of sintering of $\mathrm{CaO}$ and $\mathrm{CaSO}_{4}$ \\
\hline$M_{\mathrm{CO} 2}$ & molar mass of $\mathrm{CO}_{2}, \mathrm{~g} / \mathrm{mol}$ \\
\hline$R$ & radial position of particle, $\mathrm{m}$ \\
\hline$R_{0}$ & particle radius, $\mathrm{m}$ \\
\hline$r_{1}$ & radius corresponding to $S_{1}, \mathrm{~m}$ \\
\hline$r_{2}$ & radius corresponding to $S_{2}, \mathrm{~m}$ \\
\hline$r_{\mathrm{a}}$ & average radius of the pore, $\mathrm{m}$ \\
\hline$S$ & pore surface area in random pore model, $\mathrm{m}^{2} / \mathrm{m}^{3}$ \\
\hline$S_{0}$ & initial pore surface area of particle, $\mathrm{m}^{2} / \mathrm{m}^{3}$ \\
\hline$S_{1}$ & interface area of $\mathrm{CaCO}_{3} / \mathrm{CaO}, \mathrm{m}^{2} / \mathrm{m}^{3}$ \\
\hline$S_{2}$ & interface area of $\mathrm{CaSO}_{4} / \mathrm{CaO}, \mathrm{m}^{2} / \mathrm{m}^{3}$ \\
\hline$S_{3}$ & interface area of $\mathrm{CaSO}_{4} /$ pore, $\mathrm{m}^{2} / \mathrm{m}^{3}$ \\
\hline
\end{tabular}




\begin{tabular}{|c|c|}
\hline$T$ & reaction temperature, $\mathrm{K}$ \\
\hline$t$ & reaction time, $\mathrm{s}$ \\
\hline$t_{0}$ & sintering beginning time, $\mathrm{s}$ \\
\hline$V$ & pore volume in random pore model, $\mathrm{m}^{3} / \mathrm{m}^{3}$ \\
\hline$V_{0}$ & initial value of $V, \mathrm{~m}^{3} / \mathrm{m}^{3}$ \\
\hline$V_{\mathrm{CaCO}_{3}}^{\mathrm{M}}$ & molar volume of $\mathrm{CaCO}_{3}, \mathrm{~m}^{3} / \mathrm{mol}$ \\
\hline$v_{\mathrm{s}}$ & sulfation rate, $\mathrm{mol} /\left(\mathrm{m}^{2} \cdot \mathrm{s}\right)$ \\
\hline$X$ & sulfation conversion \\
\hline$Z_{1}$ & molar volume ratio of $\mathrm{CaO}$ to $\mathrm{CaCO}_{3}$ \\
\hline$Z_{2}$ & molar volume ratio of $\mathrm{CaSO}_{4}$ to $\mathrm{CaO}$ \\
\hline Greek & nbols \\
\hline$\alpha$ & calcination conversion \\
\hline$\varepsilon$ & porosity of particle \\
\hline$\varepsilon_{0}$ & initial porosity of particle \\
\hline$\Delta_{1}$ & thickness of $\mathrm{CaO}$ product layer when limestone is calcined without $\mathrm{SO}_{2}, \mathrm{~m}$ \\
\hline$\Delta_{1}^{\prime}$ & thickness of $\mathrm{CaO}$ product layer when limestone is calcined with $\mathrm{SO}_{2}, \mathrm{~m}$ \\
\hline$\Delta_{2}$ & $\begin{array}{l}\text { thickness of } \mathrm{CaSO}_{4} \text { product layer when limestone is calcined with } \mathrm{SO}_{2}, \mathrm{~m} \\
\text { structure parameter }\end{array}$ \\
\hline
\end{tabular}

\section{References}

[1] Chen, Y; Lu, X; Zhang, W; Wang, Q; Chen, S; Fan, X; Li, J; An experimental study on the hydrodynamic performance of the water-wall system of a 600MW supercritical CFB boiler. Applied Thermal Engineering 2018, 141: 280-287.

[2] Xu, L; Cheng, L; Zhou, Y; Wang, Q; Numerical Study of Gas-solids Flow Characteristics in a 1000 MW Supercritical CFB Boiler Octagonal Furnace. Proceedings of the Chinese Society for Electrical Engineering 2015, 35(10): 2480-2486.

[3] Anthony, EJ; Granatstein, DL; Sulfation phenomena in fluidized bed combustion systems. Progress in Energy and Combustion Science 2001, 27(2): 215-236.

[4] Adánez, J; Gayán, AP; Garcíalabiano, F; Comparison of Mechanistic Models for the Sulfation Reaction in a Broad Range of Particle Sizes of Sorbents. Industrial \& Engineering Chemistry Research 1996, 35(7): 2190-2197.

[5] Shih, S; Lai, J; Yang, C; Kinetics of the Reaction of Dense $\mathrm{CaO}$ Particles with $\mathrm{SO}_{2}$. Industrial \& Engineering Chemistry Research 2011, 50(22): 12409-12420.

[6] Han, K; Lu, C; Cheng, S; Zhao, G; Wang, Y; Zhao, J; Effect of characteristics of calcium-based sorbents on the sulfation kinetics. Fuel 2005, 84(14-15): 1933-1939.

[7] Shih, S; Hung, J; Tian-You, W; Lin, R; Kinetics of the reaction of sulfur dioxide with calcium oxide powder. Journal of the Chinese Institute of Chemical Engineers 2004, 35(4): 447-454.

[8] Ar, R; Balci, S; Sulfation reaction between $\mathrm{SO}_{2}$ and limestone: application of deactivation model. Chemical Engineering and Processing: Process Intensification 2002, 41(2): 179-188.

[9] Chen, L; Wang, C; Wang, Z; Anthony, EJ; The kinetics and pore structure of sorbents during the simultaneous calcination/sulfation of limestone in CFB. Fuel 2017, 208: 203-213.

[10] Wang, C; Chen, L; Jia, L; Tan, Y; Simultaneous calcination and sulfation of limestone in CFBB. Applied Energy 2015, 155: 478-484.

[11] Wang, C; Chen, L; The effect of steam on simultaneous calcination and sulfation of limestone in CFBB. Fuel 2016, 175: 164-171.

[12] Szekely, J; Evans, JW; A structural model for gas-solid reactions with a moving boundary. Chemical Engineering Science 1970, 25(6): 1091-1107. 
[13] Petersen, EE; Reaction of porous solids. AIChE Journal 1957, 4(3): 443-448.

[14] Hartman, M; Coughlin, RW; Reaction of Sulfur Dioxide with Limestone and the Grain Model. AIChE Journal 1976, 22(3): 490-498.

[15] Georgakis, C; Chang, CW; Szekely, J; A changing grain size model for gas-so lid reactions. Chemical Engineering Science 1979, 34(8): 1072-1075.

[16] Lindner, B; Simonsson, D; Comparison of structural models for gas-solid reactions in porous solids undergoing structural changes. Chemical Engineering Science 1981, 36(9): 1519-1527.

[17] Christman, PG; Edgar, TF; Distributed Pore-Size Model for Sulfation of Limestone. AIChE Journal 1983, 29(3): 388-395.

[18] Bhatia, SK; Perlmutter, DD; A Rondom Pore Model for Fluid-Solid Reactions: I. Isothermal, Kinetic Control. AIChE Journal 1980, 26(3): 379-386.

[19] Bhatia, SK; Perlmutter, DD; A Random Pore Model for Fluid-Solid Reactions: II. Diffusion and Transport Effects. AIChE Journal 1981, 27(2): 247-254.

[20] Mahuli, SK; Agnihotri, R; Jadhav, R; Chauk, S; Fan, L; Combined Calcination, Sintering and Sulfation Model for $\mathrm{CaCO}_{3}-\mathrm{SO}_{2}$ Reaction. AIChE Journal 1999, 45(2): 367-382.

[21] Keener, SU; Khang, SJ; Keener, TC; A Calcination and Sulfation Reaction Model for Calcium Carbonate with Sulfure Dioxide. Advances in Environmental Research 1998, 2(3): 251-268.

[22] Bhatia, SK; Perlmutter, DD; The Effect of Pore Structure on Fluid-Solid Reactions Application to the $\mathrm{SO}_{2}$-Lime Reaction. AIChE Journal 1981, 27(2): 226-234.

[23] Khinast, J; Krammer, GF; Brunner, C; Staudinger, G; Decomposition of limestone: The influence of $\mathrm{CO}_{2}$ and particle size on the reaction rate. Chemical Engineering Science 1996, 51(4): 623-634.

[24] Hsia, C; Pierre, GRS; Fan, L; Isotope study on diffusion in CaSO4 formed during sorbent-flue-gas reaction. AIChE Journal 1995, 41(10): 2337-2340.

[25] Hsia, C; St. Pierre, GR; Raghunathan, K; Fan, LS; Diffusion through $\mathrm{CaSO}_{4}$ formed during the reaction of $\mathrm{CaO}$ with $\mathrm{SO}_{2}$ and $\mathrm{O}_{2}$. AIChE Journal 1993, 39(4): 698-700.

[26] Borgwardt, RH; Sintering of Nascent Calcium Oxide. Chemical Engineering Science 1989, 44(1): 53-60.

[27] Milne, CR; Silcox, GD; Pershing, DW; Kirchgessner, DA; Calcination and Sintering Models for Application to High-Temperature, Short-Time Sulfation of Calcium-Based Sorbents. Industrial \& Engineering Chemistry Research 1990, 29(2): 139-149.

[28] Campbell, FR; Hills, AWD; Paulin, A; Transport properties of porous lime and their infiuence on the decomposition of porous compacts of calcium carbonate. Chemical Engineering Science 1970, 25(6): 929-942.

[29] Milne, CR; Silcox, GD; Pershing, DW; Kirchgessner, DA; High-Temperature, Short-Time Sulfation of Calcium-Based Sorbents. 1. Theoretical Sulfation Model. Industrial \& Engineering Chemistry Research 1990, 29(11): 2192-2201.

[30] Huizenga, DG; Smith, DM; Knudesen diffusion in random assemblages of uniform spheres. AIChE Journal 1986, 32(1): 1-6.

[31] Silcox, GD; Kramlich, JC; Pershing, DW; A mathematical model for the flash calcination of dispersed $\mathrm{CaCO}_{3}$ and $\mathrm{Ca}(\mathrm{OH})_{2}$ particles. Industrial \& Engineering Chemistry Research 1989, 28(2): 155-160.

[32] Wang, C; Zhang, Y; Jia, L; Tan, Y; Effect of water vapor on the pore structure and sulfation of CaO. Fuel 2014, 130: 60-65.

[33] Wen, CY; Noncatalytic Heterogeneous Solid Fluid Reaction Models. Industrial and Engineering Chemistry 1968, 60(9): 34-54. 